\title{
Medication Adherence and Predictors of Non-Adherence among Patients with Type 2 Diabetes Mellitus in Sohag, Egypt.
}

\author{
${ }^{1}$ Rasha Abd Elhameed Ali, ${ }^{2}$ Eman Nasr Eldin N Hamed, ${ }^{1}$ Mohamed Ali Al-Torky, ${ }^{1}$ Fouad Metry Atia \\ ${ }^{1}$ Public Health \& Community Medicine Department, ${ }^{2}$ Family Medicine Department, Faculty of Medicine, \\ Sohag University, Sohag, Egypt
}

Submission Date: 12-08-2020Ｒevision Date: 24-09-2020_Acceptance Date: 26-09-2020

\begin{abstract}
Background: Diabetes mellitus is a prevalent chronic disease with a fast-growing burden worldwide. Medication adherence is considered a cornerstone in its management and plays a major role in glycemic control and hence prevention of complications. Objective: This study aimed to determine the magnitude and predictors of medication adherence among patients with type 2 diabetes mellitus in Sohag, Egypt. Method: a cross-sectional survey was conducted among 400 diabetic patients who were presented to the outpatient clinics of El-Balyana family medicine center in Sohag for follow up. A structured questionnaire that contains questions about socio-demographic and clinical data of the participants in addition to the Arabic version of Morisky eight-item Medication Adherence Scale (MMAS-8) was used in data collection Results: Less than half the studied diabetic patients (44.5\%) were adherent to therapy. Marital status of the patient, absence of comorbid disease and diabetes complication and being educated frequently about the disease and treatment regimen were the most important predictors of medication adherence detected by the study. Conclusion: The level of medication adherence in the current study is low and sub-optimal, it implies the need for enhancing better education about the disease at short intervals to raise the level of adherence and hence enhance adequate glycemic control among diabetic patients.
\end{abstract}

Keywords: Diabetes Mellitus, Medication, adherence, predictors.

Corresponding author: Rasha Abd Elhameed Ali Email: rashaali8155@gmail.com

\section{Introduction}

Diabetes mellitus (DM) is considered one of the fastgrowing public health problems, currently 285 million persons suffer from diabetes worldwide and it is estimated that by 2030 the number of diabetic patients will reach 438 million. ${ }^{1}$ Adherence to medication is the core of diabetes management which also includes the adoption of a healthy lifestyle and diet. ${ }^{2}$ Adherence is defined by the World Health Organization (WHO) as "the extent to which a person's behavior-taking medication, following a diet, and/or executing lifestyle changes, corresponds with agreed recommendations from a health care provider". ${ }^{3}$

Adherence of diabetic patients to their medications is linked to better glycemic control and lower risk of complications. On the other hand, poor medication adherence leads to the development of micro and macrovascular complications with resulting end-organ failure (kidney, eye, heart) that affect the quality of life of diabetic patients and increase mortality rate and the direct health care cost. ${ }^{4,5}$

Non-adherence to medication is very common among patients with chronic disease as according to (WHO) report in 2003, about $50 \%$ of patients with chronic diseases adhere to their medications in developed countries and it is lower in developing countries. ${ }^{6}$ Medication adherence is influenced by various personal, cultural and institutional factors, such as patients' age, socioeconomic and educational level, the complexity of medication regimen, its side effects, cost, and availability, in addition to emotional wellbeing and social support of the patients and most of these factors are interrelated. ${ }^{7,8}$ According to the International Diabetes Federation, $15.2 \%$ of the adult population in Egypt are diabetic $(8,850,400$ persons) and it's expected that this number with be doubled in 2045. 9

Despite evidence of poor adherence to medication among diabetic patients elsewhere in Egypt, data regarding adherence of patients with type 2 diabetes mellitus in upper Egypt especially Sohag, are deficient. So, this study aims to determine the magnitude and predictors of medication adherence among patients with type 2 diabetes mellitus in Sohag, Egypt.

\section{Method}

The current study was a cross-sectional survey conducted among patients with type 2 diabetes mellitus attending outpatient's clinic of family medicine centers at El-Balyana district sohag during six months duration from 1 st December 2018 to the end of May 2019.

Patients were recruited from outpatient clinics of the Family health units of El-Balyana district, Sohag during the period of the study, when fulfilling the following inclusion criteria: 1) they were diagnosed with type 2 diabetes mellitus according to the diagnostic criteria of the 10th revision of the International Classification of Diseases (ICD-10) ${ }^{\mathbf{1 0}}$ for at least one-year duration. 2) They were on the treatment of DM for at least six months. 3) They had complete medical records. 4) Accepted to participate 
Table (1): Relation between socio-demographic characteristics of the studied diabetic patients and medication adherence in Sohag, Egypt

\begin{tabular}{|c|c|c|c|c|}
\hline \multirow[t]{2}{*}{ Factors } & $\begin{array}{c}\text { Total diabetic } \\
\text { patients }\end{array}$ & $\begin{array}{c}\text { Adherent } \\
n=178\end{array}$ & \multirow{2}{*}{ Significance test } & \multirow{2}{*}{$\operatorname{COR}(95 \% \mathrm{CI})$} \\
\hline & $n=400$ & No $(\%)$ & & \\
\hline \multicolumn{5}{|l|}{ Age: Mean (SD): 56.01(0.9) } \\
\hline$<40 \mathrm{y}$ & 33 & $22(66.7)$ & $\chi 2=22.01, p \leq 0.001$ & $7.6(3.25-7.7)$ \\
\hline $40-60 y$ & 247 & $131(53)$ & $\chi^{2}=31.7, p \leq 0.001$ & $4.3(2.58-7.1)$ \\
\hline$>60$ y (r) & 120 & $25(20.8)$ & & 1 \\
\hline
\end{tabular}

Gender
Female
Male (r)

\begin{tabular}{lr}
\hline Residence & 176 \\
Rural & 386 \\
Urban (r) & 1 \\
\hline Marital status & \\
Unmarried & \\
Married & 229 \\
Divorced or widow ( $\mathbf{r})$ & 166
\end{tabular}

$\begin{array}{llcc}924 & 95(42.4) & \chi 2=0.9, \mathrm{p}=0.3 & 0.82(0.55-1.22) \\ 176 & 83(47.2)\end{array} \quad 1$

\section{Education}

Illiterate (r)

Primary school

High school or higher (r)

386

$83(47.2)$

$14 \quad 5(35.7)$

$$
\chi 2=0.45, \mathrm{p}=0.5
$$

$1.46(0.48-4.44)$

5
29
66

$\begin{array}{rc}2(40) & \chi 2=0.35, \mathrm{p}=0.5 \\ 130(56.8) & \chi 2=31.6, \mathrm{p} \leq 0.001 \\ 46(27.7) & \end{array}$

$1.73(0.28-10.7)$

$3.4(2.3-5.26)$

229

$46(27.7)$

\section{Occupation}

Worker or governmental employee

Non- Working (r)

$\begin{array}{rrr}59 & 5(8.5) & \chi 2=32.4, \mathrm{p} \leq 0.001 \\ 315 & 151(47.9) & \chi 2=10.3, \mathrm{p} \leq 0.001 \\ 26 & 22(84.6) & \end{array}$

$0.017(0.004-0.06)$

$0.16(0.05-0.49)$ $22(84.6)$

in the study and filled a written consent. Patients were excluded if they had a history of psychiatric illness or were on anti-depressant treatment and/or using psychotropic drugs as it limits their cognitive ability. Diabetic patients were selected randomly using a systematic random sample (every third patient) technique.

Sample size: The sample size was calculated using the Epi Info 7 software, based on the following assumption: the proportion of adherence to antidiabetic medication in the study population of 37 $\%$, ( as reported by the previous study conducted in the nearby governorate, Assuit) ${ }^{11}$, level of confidence $95 \%$ and precision 5\%, and design effect 1. Accordingly, the minimal needed sample size was calculated to be 359 . Finally, 400 randomly selected type 2 diabetic patients were recruited in this study. Data collection procedure: Data were collected through personal interviews with type 2 diabetic patients from the predetermined places using a specially designed multi-item questionnaire after explaining the nature and aim of the study to eligible persons.

Study instrument: The data collection tool was a structured questionnaire that consisted of three sections: the first section included socio-demographic data of the study participants such as age, gender, residence, educational level marital state, and occupation. The second section included clinical data of the studied patients (BMI, duration since the patient was diagnosed a diabetic patient, presence or absence of comorbidity, presence or absence of complications of diabetes mellitus, whether the patient measures

$\begin{array}{lcc}97(62.2) & \chi 2=31.2, \mathrm{p} \leq 0.001 & 3.3(2.17-5.03) \\ 81(33.2) & - & 1\end{array}$

blood glucose level at home regularly or not, the period since last medical checkup and whether the patient received health education session about the disease in the last six months or not). This section also included questions about the type of antidiabetic medication taken by the patient, whether oral hypoglycemic drugs, insulin, or both, whether the patient experienced side effects of medication or not, whether the price of medication was affordable by the patient or not, and, finally the level of HA1C as an indicator of glycemic control among the study subjects was also recorded. The third section was the Arabic version of Morisky eight-item Medication Adherence Scale (MMAS-8) to measure adherence to treatment. MMAS- 8 is the latest generic self-reported, medication-taking behavior scale. The original English-language MMAS-8 and its Arabic version showed acceptable levels of reliability and validity. It consists of eight questions. Total scores obtained from MMAS-8 range from 0 to 8 , with scores of $<6$ and 6to $\leq 8$, indicating low, medium, and high adherence, respectively. Patients with total MMAS-8 scores $<6$ were considered non-adherent, while MMAS- 8 scores $\geq 6$ were considered adherent. ${ }^{\mathbf{1 2 , 1 3}}$

\section{Statistical Analysis}

The statistical analysis was carried out using SPSS software for Windows (version 22.0). Regarding, adherence to therapy, patients were divided into two groups those who were adherent with medication (score of 6 or higher), and the second group included patients with poor adherence (a score of less than 6). Descriptive statistics as frequencies, percentages, 
Table (2): Relation between clinical profile and therapy related characteristics of the studied diabetic patients and adherence to medication in Sohag, Egypt

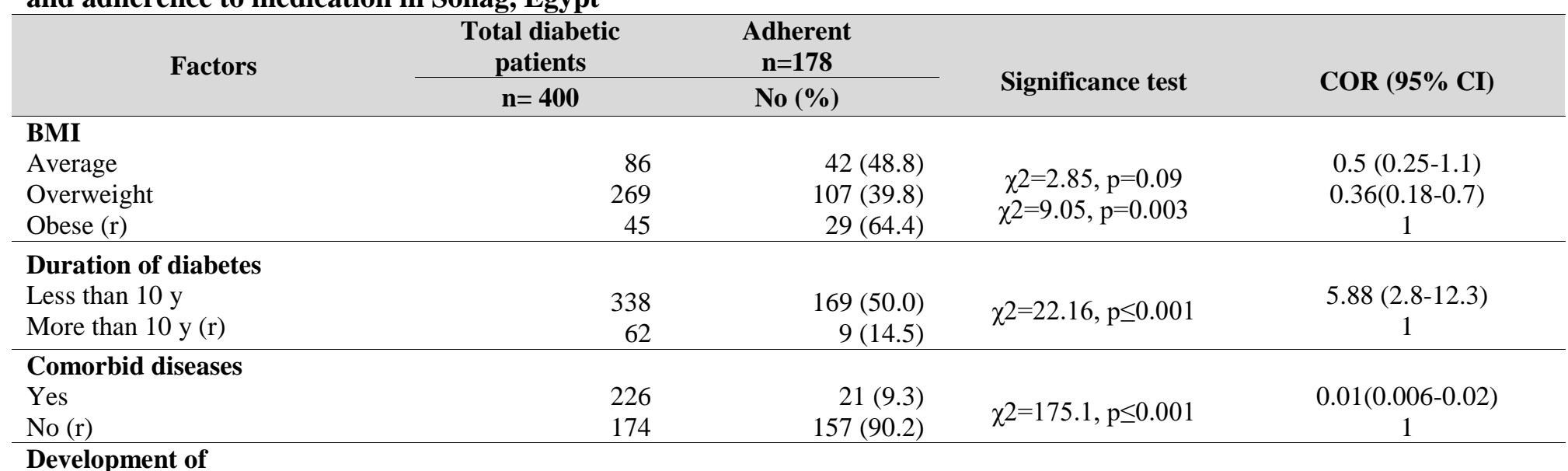

complications due to
DM
Yes
No $(r)$

Measure blood glucose

level at home

Yes 224

No (r)

224

$10(4.5)$

$\chi 2=58.3, p \leq 0.001$

0.002 (0.001-0.006) $168(95.5)$

Last medical check up

$3 \mathrm{~m}$ ago or earlier

More than $3 \mathrm{~m}$ ago (r)

Receiving health

education during last

6m

No

Twice or more(r)

255

$51(20.0)$

$\chi 2=123.6, p \leq 0.001$

$0.037(0.02-0.06)$

Therapy related factors:

Type of antidiabetic

medication

Oral hypoglycemic

Insulin

both (r)

$145-127(87.6)$

$164(73.2)$

$\chi 2=118.8, p \leq 0.001$

$31.6(16.9-58.8)$

176

$14(8.0)$

$127(87.6)$

$99(62.3)$

$\chi 2=38.3, p \leq 0.001$

$3.73(2.46-5.66)$

Ever experienced

medication side effects

Yes

No (r)

$\begin{array}{rr}224 & 114(50.9) \\ 64 & 34(53.1)\end{array}$

$30(26.8)$

$\chi 2=17.1, \mathrm{p} \leq 0.001$

$2.8(1.7-4.6)$

112

$\chi 2=11.1, \mathrm{p} \leq 0.001$

$3.09(1.6-5.9)$

1

Price of medicine

Affordable

Unaffordable (r)

$259 \quad 55(21.2)$

$123(87.2)$

$\chi 2=120.4, p \leq 0.100$

$0.039(0.02-0.07)$

HbA1C

Controlled $\leq 7 \%$

Uncontrolled $>7 \%$ (r)

99

87 (87.9)

$91(30.2)$

$\chi 2=71.7, p \leq 0.001$

16.73(8.7-32.1)

301

$90(88.0)$

102

298

88 (12.0)

$\chi 2=78.02, p \leq 0.001$

$34.03(4.6-249.9)$

means, and standard deviations were calculated.

Association between socio-demographic and clinical

factors of the studied diabetic patients and their adherence to therapy were tested using chi-square test and Binary logistic regression analysis was done. The statistical difference was considered significant when p-value was less than 0.05 .

\section{Ethical considerations}

The researchers complied with the International Guidelines for Research Ethics. The approval for conducting this study from the Scientific Research Ethical Committee of the Faculty of Medicine, Sohag University was obtained followed by approval from the $\mathrm{MOH}$ for conducting the study in Balyana family medicine centers. Besides, informed consent was purpose of the study and ensuring confidentiality and anonymity.

\section{Results}

A total of 400 patients with type $2 \mathrm{DM}$ were enrolled in the current study. The mean age of the studied patients was $56.01 \pm 10.9$, more than half $(56 \%)$ of them were females and the majority $(96.5 \%)$, were rural residents. Detailed socioeconomic and clinical data of the studied patients and relation with medication adherence are displayed in tables (1 and 2).

Based on eight items Morisky Medication Adherence Scale (MMAS-8), $44.5 \%$ of the studied patients with type 2 DM (187 patients) were adherent to antidiabetic taken from the study participants after explaining the Table (3): Final model of the logistic regression analysis of predictors of adherence to medications among the studied diabetic patients in Sohag, Egypt 


\begin{tabular}{|c|c|c|c|}
\hline Predictor & B & $P$ value & $\operatorname{AOR}(95 \% \mathrm{CI})$ \\
\hline \multicolumn{4}{|l|}{ Marital status } \\
\hline Unmarried & 5.5 & 0.002 & $71.4(5.09-.577 .3)$ \\
\hline Married & 2.03 & 0.003 & $16(2.5-108.7)$ \\
\hline Widow or divorced $(\mathrm{r})$ & - & - & - \\
\hline \multicolumn{4}{|c|}{ Presence of complications to diabetes } \\
\hline Yes & 4.4 & $\leq 0.001$ & $0.002(0.00-0.16)$ \\
\hline No $(r)$ & - & - & - \\
\hline \multicolumn{4}{|l|}{ Presence of associated disease } \\
\hline Yes & 3.2 & $\leq 0.001$ & $0.04(0.01-0.15)$ \\
\hline No $(r)$ & - & - & - \\
\hline
\end{tabular}

Had health education session in the

previous 6 months

Yes

No (r)

medication. Regarding socio-demographic

characteristics of the study participants, the proportion of diabetic patients who were adherent to medication was significantly higher among participants who were $<40$ years or between 40 and 60 years compared to older patients $(66.7 \%$ and $53 \%$ respectively with $\mathrm{P}$ value $=0.000)$, married $(56.8 \%$ with $\mathrm{P}$-value $=0.000)$, had high school or higher education $(84.6 \%$, p value $=$ $0.000)$ and were workers or governmental employees $(62.2 \%$ with $p$ value $=0.00)$. Regarding the association between clinical data of the studied patients and adherence to their medication, presence of other comorbid diseases, development of complications to diabetes mellitus, measuring blood glucose level at home regularly, conducting medical checkup in the previous six months, having health education session in the previous six months, were significantly associated with adherence to therapy among the studied patients $(\mathrm{P}$ value $=0.000)$. regarding treatment regimen, those who were treated with insulin, patients who can afford the price of medication, and those who experienced no side effects of medications were significantly more adherent to therapy than other patients ( $p$-value $0.00, \quad p$ - value 0.000 respectively significantly higher proportion of adherent patients measured blood glucose level at home $(73.2 \%, \mathrm{P}$ value $=0.0,0)$

Table (3) shows the association of HbA1C of the studied diabetic patients with adherence to antidiabetic medications. Medication adherence was significantly associated with a low level of $\mathrm{HbA1C}$ and hence better glycemic control among the study subjects, as $78 \%$ of the adherent diabetic patients had a good level of HAIC $(\leq 7 \%)$ compared to $22 \%$ of the non-adherent patients ( $\mathrm{P}$-value $<0.05)$.

Final model of bivariate logistic regression analysis of predictors of adherence to antidiabetic medications among the study participants is illustrated in table 4 . Marital status, absence of complications of diabetes, absence of comorbid disease, and receiving health education sessions in the previous six months were the most important predictors of adherence to therapy among the studied patients.

\section{Discussion}

1

$4.4(1.07-18.3)$

Recent reports from World Health Organization stated that the impacts of non-adherence to therapy among diabetic patients are so alarming and efforts directed to improve adherence to therapy are better than developing new medical treatment. ${ }^{14}$ This is because however new treatments are developed when patients don't take them no results in reducing complications, mortality and disease cost are gained. ${ }^{14}$

In the current study, less than half the studied patients with type 2 diabetes mellitus (44.5\%) were adherent to treatment. These results are lower than the results of Ibrahim et al., in Alexandria who reported that about $57 \%$ of the study patients always took their medication as prescribed and on time. ${ }^{15}$ Moreover, our results are much lower than the results of Heissam et al. in Ismailia ${ }^{16}$ and Taleb and El-Shazly in Assuit, ${ }^{11}$ who reported that $74 \%$ and $78 \%$ of the studied patients respectively were adherent to therapy. However, our results are higher than the results of Shams and Barakat, in Mansoura ${ }^{17}$, who found that only $38.9 \%$ of the studied diabetic patients in Mansoura University hospital were adherent to therapy.

Compared to other Arab and African countries, the rate of medication adherence in the current study is higher than that reported by Khan et $\mathrm{al}^{18}$ and Aloudah et al., ${ }^{19}$ in Saudia Arabia (32\% and $40 \%$ respectively), lower than the adherence level reported in in kuwait $(73.9 \%)^{20}$ and in Ethiopia $(54.8 \%)^{21}$, and similar to Waari et al., in Kenya (45.5\%). ${ }^{22}$

Of the 27 studies included in Krass et al., review, medication adherence ranged from 38.5 to $93.1 \%$, and only six out of 27 studies $(22.2 \%)$ reported prevalence of adherence of $\geq 80 \%$ among their study population. ${ }^{23}$ Comparing the rate of adherence among patients with type $2 \mathrm{DM}$ is difficult between different countries and between different localities in the same country. This may have resulted from difference in lifestyle, the policies and strategies adopted by different countries, awareness differences in the importance of adherence to medication, using different tools in measuring adherence and depending on patient self-report which is not always accurate. However, the reported rate of adherence in the current study remains very low and suboptimal especially when considering that depending on patient self- 
report is usually associated with an over-estimated adherence level.

Inadequate control of blood glucose level can lead to several cardiovascular and nervous disorders which are leading causes of mortality of diabetic patients and account for the higher percent of expenses by those patients. ${ }^{4}$ Adherence to therapy markedly reduces the risk of complications among patients with type $2 \mathrm{DM}$ mainly by affecting glycemic control. ${ }^{24}$ In agreement with many previous studies ${ }^{11,17,19,20,22}$, we found a significant inverse relationship between high adherence scores and lower assayed values of glycosylated haemoglobin (HbA1C) that indicated better glycemic control amongst the studied diabetic patients.

In terms of socio-demographic factors that affect adherence level, we found no significant association between medication adherence and age, gender, residence, education, and occupation of the study participants. Our results indeed, support previous research that fail to identify any significant association between these factors and adherence to therapy among patients with type $2 \mathrm{DM} .^{11,17,19,22,25}$

Inconsistent with the previously mentioned studies, unmarried and married patients were significantly more adherents to therapy than, widow or divorced patients in the current study. The effect of patients' marital status on adherence to therapy is still unclear, but it has been suggested that family support may be a significant factor. It was suggested that married individuals tend to receive more and better health care than do unmarried. ${ }^{26,27}$ Moreover, a study that assessed drug adherence in Iranian patients with chronic diseases, have identified marriage as a significant factor in improving medication adherence. $^{28}$

Patient adherence to therapy is markedly influenced by patient knowledge about disease pathology, side effects and complications and the principle of therapy that is acquired by health education. In this study diabetes health education in the prior six months was significantly associated with adherence to treatment; this is supported by results of many previous studies. ${ }^{17,18,21,25}$ This means that efforts in equipping diabetes clinics with oriented and well-trained health workers are beneficial in improving the awareness of the diabetic patients about their disease and hence improving adherence to therapy.

Findings of the current study collaborated with other studies in indicating an inverse relation between diabetes-related complications and adherence to therapy ${ }^{29,} 30,31$ suggesting that the development of complications is not only a result of poor adherence but could also worsen non-adherence by a huge percent.

Complex treatment regimens that includes different drugs treating more than one disease are difficult to follow and adhere to, in agreement with previous studies $^{30,32}$, we found that diabetic patients who reported the presence of other comorbid disease were significantly less adherent to therapy which implies the need for better follow-ups and regular monitoring of adherence to therapy of such patients who are more liable to serious complications and subsequent higher mortality.

\section{Conclusion}

The level of adherence to therapy in the current study was suboptimal as less than half the studied patients with type 2 diabetes mellitus were found adherent to medication. The marital status of the patient, the absence of comorbid disease and diabetes-related complications and being educated frequently about the disease and treatment regimen were the most important predictors of medication adherence detected by the study.

\section{Recommendations}

Identifying the degree of adherence to therapy and predictors of optimal adherence among diabetic patients is necessary to enable stakeholders to take all the needed initiatives to tackle these factors. The current study enlightens us about the importance of providing regular follow-ups to diabetic patients which includes promotion of health education services about complications of the disease and the benefits of adherence to therapy in enhancing better glycemic control and hence reducing complications of the disease. The provided health services should also include regular and thorough monitoring of adherence to therapy especially for patients with associated comorbid diseases or socially disadvantaged as the widow or divorced patients

\section{Acknowledgements}

Our sincere gratitude is expressed to diabetic patients for accepting to participate in this study.

Conflict of interests: None

\section{References:}

1. International Diabetes Federation, Middle East, and North Africa 2015.

2. Ahmad NS, Ramli A, Islahudin F, Paraidathathu T. Medication adherence in patients with type 2 diabetes mellitus treated at primary health clinics in Malaysia. Patient Preference and Adherence. 2013 Jun 17; 7:525-530.

Google Scholar.

3. World Health Organization. Report on medication adherence: Geneva, WHO; 2003. [Google Scholar]

4. Chisholm-Burns MA, Spivey CA. The 'cost' of medication non adherence: consequences we cannot afford to accept. Journal of the American Pharmacists Association: JAPhA. 2012; 52(6):823-6.

5. Nonogaki A, Heang H, Yi S, Pelt MV, Yamashina $\mathrm{H}$ et al. Factors Associated With Medication Adherence Among People With Diabetes Mellitus in Poor Urban Areas of Cambodia: A Cross-Sectional Study. PLoS One. . 2019;14(11):e0225000. doi: 10.1371.

6. Asti, T. Patients Adherence: Important Factor in the succesfull of treatment (Kepatuhan Pasien: Faktor Penting dalam Keberhasilan Terapi). Info POM. 2006; 7: 1-3.

7. Ali M, Alemu T, and Sada O. Medication adherence and its associated factors among diabetic patients at Zewditu Memorial Hospital, Addis Ababa, Ethiopia. BMC $\begin{array}{llll}\text { Research } & \text { Notes. } 2017 ; & 10 \text { : } 676 .\end{array}$ https://doi.org/10.1186/s13104-017-3025-7

8. Baghikar S, Benitez A, Fernandez Piñeros P, Gao Y, Baig AA. Factors Impacting Adherence to Diabetes 
Medication Among Urban, Low Income MexicanAmericans with Diabetes.. J Immigr Minor Health. 2019 ; 21(6):1334-1341. doi: 10.1007/s10903-019-00867-9.

9. International Diabetes Federation, Middle East, and North Africa 2020.

10. Alberti, K.G.; Zimmet, P.D. Diagnosis and classification of diabetes mellitus and its complications. Part 1: Diagnosis and classification of diabetes mellitus provisional report of a WHO consultation. Diabet. Med.1998; 15: 539-553. [CrossRef]

11.Teleb S, El-Shazly A. Compliance of diabetic Patients to therapeutics regimen. Ass. Univ. Bull. Environ. Res.2003; 6 (2): 125-133

12.Morisky DE, Nag A, Krousel-wood M, Ward HJ. Predictive validity of a medication adherence measure in an outpatient setting. J Clin Hypertens. 2008; 10: 348354.

13. Ashur ST, Shamsuddin K, Shah SA, Bosseri S, Morisky DE. Reliability and known-group validity of the Arabic version of the 8-item Morisky Medication Adherence Scale among type 2 diabetes mellitus patients. East Mediterr Health J. 2015; 21: 722-8.

14. World Health Organization. Adherence to long term therapies. Time for action. World Health Organization. 2003

15.Ibrahim NK, Attia SG, Sallam SA, Fetohy EM, et al. Physicians' therapeutic practice and compliance of diabetic patients attending rural primary health care units in Alexandria. J Family Community Med. 2010 17(3):1218. PubMed | Google Scholar.

16.Heissam K, Abuame Z, El-Dahshan N. Patterns and obstacles to oral antidiabetic medications adherence among type 2 diabetics in Ismailia, Egypt: a cross section study. Pan African Medical Journal. 2015; 20:177 doi:10.11604/pamj.2015.20.177.4025

17.Shams M, Barakat E. Measuring the rate of therapeutic adherence among outpatients with T2DM in Egypt. Saudi Pharmaceutical Journal .2010; 18: 225-232

18. Khan A, Al-Abdul Lateef $\mathrm{Z}, \mathrm{Al}$ Aithan $\mathrm{M}, \mathrm{Bu}-$ Khamseen M, Al Ibrahim I and Khan S. Factors contributing to non-compliance among diabetics attending primary health centers in the Al Hasa district of Saudi Arabia. J Family Community Med.2012 Jan-Apr; 19(1): 26-32. doi: 10.4103/2230-8229.94008

19. Aloudah N, Scott N, Aljadhey H, Araujo-Soares V, Alrubeaan K, Watson M. Medication adherence among patients with Type 2 diabetes: Amixed methods study. PLOS ONE. 2018

20.Al-Maged H, Ismael A, Al- Katlan H, El- Shazly M. Adherence of Type-2 Diabetic Patients to Treatment. Kuwait Medical Journal. 2014; 46(3): 252-232

21.Ali M, Alemu T and Sada O. Medication adherence and its associated factors among diabetic patients at Zewditu Memorial Hospital, Addis Ababa, Ethiopia. BMC Res Notes; 2017: 10:676
22.Waari G, Mutai J, Gikunju J. Medication adherence and factors associated with poor adherence among type 2 diabetes mellitus patients on follow-up at Kenyatta National Hospital, Kenya. Pan African Medical Journal. 2018; 29:82.

23.Krass I , Schieback P, Dhippayom T. Adherence to Diabetes Medication: A Systematic Review. Diabet Med.. 2015; 32(6):725-37. doi: 10.1111/dme.12651.

24.Benford M, Miligan G, Pike J, Anderson P, piercy J, fermer $X$. Fixed- dose combination antidiabetic therapy: real- world factors associated with prescribing choices and relationship with patient satisfaction and compliance. ADV Ther.2012; 29: 26-40

25.Bagonza J, Rutebemberwa E, Bazeyo W. Adherence to anti diabetic medication among patients with diabetes in eastern Uganda; a cross sectional study. BMC Health Services Research ; 2015:15:168 DOI 10.1186/s12913015-0820-5

26.Freedman VA, Aykan H, Wolf DA, Marcotte JE. Disability and home care dynamics among older unmarried Americans. J Gerontol B Psychol Sci Soc Sci. 2004;59(1):S25-33.

[PubMed] [CrossRef] [Google Scholar]

27.Spillman BC, Pezzin LE. Potential and active family caregivers: changing networks and the "sandwich generation." Milbank Q. 2000;78(3):347-374, table of contents. [PMC free article] [PubMed] [Google Scholar] 28.Dabaghian FH, Rassouli M, Sadighi J, Ghods R. Adherence to prescribed medications of Iranian traditional medicine in a group of patients with chronic disease. J Res Pharm Pract. 2016;5 (1):52-57. doi:10.4103/2279042X.176563. [PMC free article] [PubMed] [CrossRef] [Google Scholar]

29.Nonogaki A, Heang H, Yi S, Pelt M,Yamashina H, Taniguchi C, Nishida et al., Factors associated with medication adherence among people with diabetes mellitus in poor urban areas of Cambodia: A cross-sectional study. PLOS ONE. 2019 https://doi.org/10.1371/journal.pone.0225000

30. Demoz GT, Berinverseha AB, Woldu MA, Yifter H, Shibeshi W, Engidawork, E. Drug therapy problems, medication adherence and treatment satisfaction among diabetic patients on follow-up care at Tikur Anbessa Specialized Hospital, Addis Ababa, Ethiopia. PLoS One. 2019; 14(10)

31.Teklay G (2013) Patients at Jimma University Specialized Hospital, Southwest. J Med Sci 13: 578-584. [Google Scholar

32.Nur SA, Azuana R, Farida I, Thomas P. Medication adherence in patients with type 2 diabetes mellitus treated at primary health clinics in Malaysia. Patient Prefer Adherence. 2013; 7:525-30. https://doi.org/ 10.2147/PPA.S44698 PMID: 23814461 